\title{
SUBLINGUAL MISOPROSTOL FOR CERVICAL PRIMING PRIOR TO VACUUM EVACUATION OF FIRST TRIMESTER MISSED ABORTION: A RANDOMIZED COMPARATIVE STUDY
}

\author{
Osama M. Warda, MD
}

Obstetrics \& Gynecology Department- Faculty of Medicine- Mansoura University-EGYPT

\section{ABSTRACT}

Objective: This study aimed to compare sublingual misoprostol (as a new route of administration) to the vaginal route for pre-operative cervical priming in vacuum evacuation of first trimester missed abortion.

Design: Prospective randomized clinical study

Setting: Private practice in Domyat city during the period throughout March 2005 to September 2006.

Methods: Eighty women with missed abortion (fetal death or blighted ova) of gestational age $\leq 2$ weeks were randomized by a computer-generated model to receive $400 \mu \mathrm{g}$ of misoprostol (Misotac (B) SIGMA) either sublingually or vaginally 3 hours prior to manual vacuum aspiration (MVA) using the IPAS bivalve instrument with its plastic cannulas. The primary outcome measure was the degree of cervical dilatation, and secondary outcomes included the cervical resistance to dilate from $3-8 \mathrm{~mm}$ (i.e. poor priming) indicated by the need to use the traditional metal Hegar's dilators instead of the plastic Karman cannulas, intra-operative blood loss and incidence of pre-operative side-elfects. Results: There was no significant difference in the baseline cervical dilatation (sublingual: $7.6 \pm 1.3 \mathrm{~mm}$; vaginal: $7.7 \pm$ $0.73 \mathrm{~mm}$ ), cervical resistance to dilate from 3 to $8 \mathrm{~mm}$ with plastic Karman camnulas and need to use metal Hegar's dilators with some force (sublingual: 8 cases (20\%); vaginal: 7 cases $(17.5 \%)$, and total blood loss (sublingual: $52.1 \pm 20.2 \mathrm{ml}$; vaginal: $48.3 \pm 12.3 \mathrm{ml}$ ). Pre-operative side-effects were also similar.

Conclusions: Both sublingual and vaginal misoprostol are eflective in cervical priming hefore surgical terminatton of pregnancy in the first trimester. Sublingual misoprostol has the advantage of being more convenient to administer and may be more suitable for day surgery.

Key Words: cervical priming-misoprostol- sublingual-vaginal .

\section{INTRODUCTION}

Surgical evacuation is currently the standard management for termination of pregnancies in the first trimester in many parts of the world. It is considered to be safe and effective with a success rate of $>95 \%$ (1). However, it is associated with major morbidity in $1 \%$ of women and minor morbidity in $10 \%{ }^{(2)}$. A more recent study of 170000 first trimester abortions carried out in New York City, USA reported that $<0.1 \%$ of the women experienced serious complication requiring hospitalization (3). It might appear that the incidence of severe morbidity has decreased recently in some of the countries in the developed world. Another more recent study, however, showed that the incidences of uterine perforation, blood transfusion and pelvic infection were $0.24 \%, 0.97 \%$ and $1.69 \%$ respectively (1) Therefore the incidences of complications vary in different centers. Although rare, the complications associated with surgical evacuation can affect the reproductive health of a substantial number of women, especially taking into consideration that 40-50 million abortions are performed annually(4).

Corresponding author : Osama M. Warda, MD, Corniche El-nil; Al-A'sar District; Al - Maa'had Al-dini Strect- Domyat City . EGYPT, E- mail: Om2warda@yahoo.com 
And many of these abortions are done in areas where facilities and expertise are lacking. The procedure of manual vacuum aspiration (MVA) is associated with fewer complications than using the traditional dilation and curettage. However, the risk is increased when difficulty is encountered during cervical dilatation at vacuum aspiration, especially in nulliparous patients (5). Various methods have been used for cervical priming before vacuum aspiration including laminaria tent, mifepristone and prostaglandin analogues. Nowadays, vacuum aspiration is often performed as day-patient surgery. Laminaria tent has to be inserted for $12 \mathrm{~h}$ and mifepristone has to be taken for $36-48 \mathrm{~h}$ to have adequate cervical priming effect. Therefore they are less convenient for day-patients. Prostaglandin analogues are the cervical priming agents of choice and misoprostol has been studied for this purpose ${ }^{(6-8)}$. Both vaginal and oral administration were found to be useful ${ }^{(9)}$. It was found that $400 \mu \mathrm{g}$ misoprostol given $3 \mathrm{~h}$ before the procedure was the optimal dose for vaginal application(10-12a,b). However, oral administration is more convenient. It can avoid a vaginal examination in a busy day-patient surgery admission clinic and is more acceptable to women (13). Recently, it has been shown that oral administration of $400 \mu \mathrm{g}$ misoprostol $3 \mathrm{~h}$ before the vacuum aspiration is as effective as a similar regimen of vaginal misoprostol (9). However, administration of oral drug with water 3 hours before operation may cause problems if the patient undergoes the operation under general anesthesia.

A new route of sublingual administration of misoprostol in medical abortion has been recently studied (14 b, c). Misoprostol is absorbed through the vaginal mucosa when administered vaginally. The buccal muscosa, being very vascular, should be able to serve the same purpose. The misoprostol tablet is very soluble in water and dissolves within 10-15 min when administered under the tonguc. Sublingual administration of misoprostol avoids the first-pass effect via the liver as in oral administration. A pharmacokinetic study showed that sublingual misoprostol was absorbed as rapidly as oral misoprostol and morc rapidly than vaginal misoprostol (14a). The peak serum concentration alter sublingual misoprostol and the area under the curve was also significantly higher than those after oral or vaginal misoprostol. It has been shown that sublingual misoprostol is effective in medical abortion and the management of miscarriage (14b,c-15). Sublingual misoprostol is convenient to use, avoids vaginal administration and avoids the ingestion of water before anesthesia. It is the aim of this randomized study to compare the efficacy of sublingual with vaginal misoprostol for pre-operative cervical priming before surgical termination of pregnancy in the first trimester.

\section{MATERIALS \& METHODS}

A total of 80 pregnant women diagnosed by ultrasound as missed abortion (fetal demise or blighted ovum) with gestational age 12 weeks or less. The gestational age was established by a reliable menstrual history and confirmed by a physical examination and ultrasound examination. All the patients were following their pregnancies in a private clinic in Domyat city and were diagnosed during the period from March 2005 to September 2006. All subjects gave informed consent after the study was explained to them. Criteria for inclusion were a normal general and gynecological history and physical examination. Women were excluded if they were taking long-term medication, had an intrauterine contraceptive device, or allergic to misoprostol.

The 80 women were allocated to the sublingual group and vaginal group by computer-generated random numbers. Each woman included was admitted to the hospital on the morning of the surgical cvacuation. Misoprostol $400 \mu \mathrm{g}$ was given either sublingually or vaginally $3 \mathrm{~h}$ before the 
scheduled operation. Manual vacuum aspiration (MVA) was performed by using the IPAS (International Project Assistance Service; USA) bivalve instrument with its plastic cannulas with sizes from 4 to $9 \mathrm{~mm}$. The blood pressure, pulse rate. temperature and the side-effects were recorded before the operation. The operation was performed under conscious sedation. All subjects were given i.v. nalbuphine hydrochloride (Nalufin(B) $10 \mathrm{mg}$ and midazolam (Midathetic(B)) $5 \mathrm{mg}$ before the operation. The cervical internal os was gently dilated using the plastic Karman cannula/curette from size 3 to size $8 \mathrm{~mm}$ consecutively. The toughness (poor priming) of the cervix is measured by its resistance to dilation by the plastic Karman cannula/curette and requiring metal Hegar's dilators to be dilated. Vacuum was created in the syringe barrel then connected to the last introduced cannula via the appropriate adaptor when the cervix was adequately dilated $(8 \mathrm{~mm})$. Vacuum was then transmitted to uterus by releasing the syringe valve, and then aspiration curettage was performed until grittiness was felt indicating complete evacuation. When the $60 \mathrm{ml}$ syringe barrel was full, the syringe only (without the cannula) was withdrawn and changed. The intra-operative blood Joss was measured as the volume of the uterine aspirate after sieving away the products of conception. The women were observed for $3 \mathrm{~h}$ before discharge from the hospital.

The primary outcome measure was the pre-operative cervical dilatation and was used to calculate the sample size required. The intra-operative blood loss and side-effects were compared. A previous study using similar doses of vaginal misoprostol showed that the baseline dilatation was $7.2 \mathrm{~mm}$ and the SD was $1.4 \mathrm{~mm}$ (9). A difference of $1 \mathrm{~mm}$ in baseline dilatation is considered as clinically significant. Therefore, a sample size of 36 in each arm will have a power of 0.8 at the $5 \%$ significance level to detect such a difference in baseline dilatation. Assuming that $10 \%$ of the subjects' data cannot be used for analysis, the total number of subjects required is 40 .

Statistical analysis was done using SPSS 10.0 lor Windows Statistical Package. Differences in continuous variables were analyzed with Student's $t$-test for normally distributed data and the Mann-Whitney $U$-test for skewed data. Differences in discontinuous variables were analyzed by Chi sparetest and the Fisher exact test as appropriate. Datit were expressed as mean ( \pm SD), median (range), or number $(\%) . P$ (two-tailed) $<0.05$ was considered statistically significant.

\section{RESULTS}

A total of 98 women who were scheduled for vacuum evacuation because of missed abortion were interviewed during the study period. Five women did not meet the inclusion criteria because the gestation was found to be $>12$ weeks. Thirteen women did net want to join because they were worried about the effectiveness and side-eflects of sublingual misoprostol. Eighty women were eligible and agreed to participate in the study. There was no signilican difference in the demographic characteristics between the two groups of women (Table I). The lindings at operation are summarized in Table II. There was no significant difference in the baseline cervical dilatation between the two groups. The median dilatation for both groups was $8 \mathrm{~mm}$. The blood loss was also comparable between the two groups. Side-effects were similar in the two groups of women (Table III). Nausea was the commonest gastrointestinal side-effect. Vomiting and diarrhoea were uncommon. Most women complained of abdominal pain and some of them started to bleed before the operation. None of them passed the product of conception before the operation. No significant complication was reported in these 80 women. 


\section{DISCUSSION}

Surgical abortion using vacuum aspiration is still the standard method for termination of pregnancy in the first trimester in many parts of the world. Cervical priming has been shown to result in a shorter operation time, less blood loss and easier mechanica! dilatation $(6,9,16)$ and these may reduce the incidence of complications associated with surgical abortion including cervical injury, uterine perforation, hemorrhage and incomplete abortion ${ }^{(17,18)}$. Although the major complication rate has been shown to be as low as $0.1 \%$ in one study ${ }^{(6)}$, it does not mean that it is not a significant clinical problem when we take into consideration that there are 40-50 million abortions occurring annually ${ }^{(4)}$. Women who undergo this minor procedure do not expect and will not accept the major complications that may affect their fertility or long-term reproductive potential. Therefore, there is a need to discover methods that can decrease the difficulties and complications of this particular operation.

Pharmacological agents have the advantage over osmotic dilators as cervical priming agents since the former does not require trained medical personnel to administer. Mifepristone and prostaglandin El analogues are elfective cervical priming agents $(6,8)$. However, milepristone is expensive, not available in many countrics including Egypt and has the disadvantage of requiring $36-48 \mathrm{~h}$ for adequate cervical priming effect. Therefore, prostaglandin $E_{1}$ analogue is usually the drug of choice. It takes a few hours for its action and is convenient for surgical evacuation performed as a day case. Misoprostol is the drug of choice- although it is not licensed for this purpose- because it is cheap and stable at room temperature. A randomized controlled trial has shown that both misoprostol and gemeprost are effective cervical priming agents in the first trimester, yet misoprostol was associated with fewer gastrointestinal side-effects ${ }^{(19)}$
Various routes of administration of misoprostol have been used for cervical priming in the first trimester. Both oral and vaginal routes were shown to be equally effective when given $3 \mathrm{~h}$ before the vacuum aspiration ${ }^{(9)}$. However, both the oral and vaginal routes have drawbacks. Some women found vaginal administration of drug inconvenient and unacceptable $\mathrm{e}^{(13)}$ and it is more convenient to give a drug by mouth in a day surgery setting. At the same time, it is better to avoid oral intake of fluid before operation, especially if this is done under general anesthesia. Sublingual misoprostol can avoid the uncomfortable vaginal application and oral intake of fluid before operation. Its clinical effectiveness in cervical priming was proven to be the same as vaginal misoprostol in this study.

Vaginal bleeding and abdominal pain were the commonest side-effects after misoprostol. These side-effects are undesirable because it may affect the acceptability of the method. Severe abdominal pain and heavy bleeding may warrant an emergency vacuum aspiration before the scheduled time. Sometimes the woman may pass the products of conception before the operation. Additional manpower may be required to handle these situations and this may affect the smooth ruming of the day surgery schedule. In this study, very few women complained of heavy bleeding or severe abdominal pain and none of the women passed the products of conception, which illustrated that both regimens are good for the purpose of cervical priming before first trimester surgical termination of pregnancy in a day surgery setting.

In conclusion, both sublingual and vaginal misoprostol are effective routes of administration for cervical priming prior to surgical termination of pregnancy in the first trimester. Sublingual misoprostol has the advantage of being more convenient to administer and may be more suitable for day surgery. 


\section{REFERENCES}

1. Child TJ, Thomas J, Rees M and MacKenzie IZ Morbidity of first trimester aspiration termination and the seniority of the surgeon. Hum Reprod (2001); 16,875-878.

2. Royal College of General Practitioners and the Royal College of Obstetricians and Gynaecologists Induction abortion operations and their early sequelae. J R Coll Gen Pract (1985); 35,175-180.

3. Hakim-Elahi E, Tovell HM and Burnhill MS Complications of first trimester abortion: a report of 170,000 cases. Obstet Gynaecol (1990); 76,129-135.

4. World Health Organization Safe Abortion: Technical and Policy Guidance for Health Systems. World Health Organization, Geneva, (2003); p 7.

5. Osama M. Warda, M. El-Shafie, A. Mashali, and H. Shalan Manual Vacuun Aspiration (MVA) in the Management of incomplete abortion: A Tool to Improve Health Service. MD THESIS. Obstetrics \& Gynecology Dept. Mansoura University, (1999); (116)

6. El-Refaey E, Calder L, Wheatley DN and Templeton A Cervical priming with prostaglandin $\mathrm{El}$ analogues, misoprostol and gemeprost. Lancet (1994); 343,1207.

7. Ngai SW, Au-Yeung KC, Lao T and Ho PC Oral misoprostol versus vaginal gemeprost for cervical dilatation prior to vacuum aspiration in women in the sixtl1 to twelfth week of gestation. Contraception (1995); 51, 347-350.

8. Ngai SW, Au-Yeung KC, Lao T and Ho PC Oral misoprostol versus mifepristone for cervical dilatation before vacuum aspiration in first trimester nulliparous pregnancy: a double blind prospective randomized study. $\mathrm{Br} J$ Obstet Gynaecol (1996); 103,112 .

9. Ngai SW, Chan YM, Tang OS and Ho PC The use of misoprostol for pre-operative cervical dilatation prior to vacuum aspiration: a randomized trial. Hum Reprod (1999); 14,2139.

10. Fong YF, Singh $K$ and Prasad RNV A comparative study using two doses regimens $(200 \mu \mathrm{g}$ or $400 \mu \mathrm{g})$ of vaginal misoprostol for pre-operative cervical dilatation in first trimester nulliparac. $\mathrm{Br} J$ Obstet Gynaecol (1998); 105,413.

11. Singh K, Fong YF, Prasad RNV and Dong F Randomized trial to determine optimal dose of vaginal misorprostol for preaboriton cervical priming. Obstet Gynecol (1998); 92.795-798.

12a.Singh K. Fong YF. Prasad RNV and Dong F Evacuation interval after vagimal misoprostol for preabortion cervical priming: a randomized trial. Obstet Gynecol (1999a) ; 94,431-434.

12b.Singh K, Fong YF, Prasad RNV and Dong F Vaginal misoprostol for pre-abortion cervatil priming: is there an optimal evacuation lime interval? Br. J Obstet Gynaccol (19996) : 106. 266-269.

13. Ho PC, Ngai SW, Liu KL and Ho PC Viginal misoprostol compared with oral misoprostol in termination of second trimester pregnancy. Obstel Gynecol (1997); 90,735-738.

14a.Tang OS, Schweer H, Seyberth NW, Lee SWH and Ho PC Pharmacokinetics of different routes of administration of misoprostol. Hum Reprod (2002a); 17, 332-336

14b.Tang OS, Miao BY, Lee SWH and Ho PC Pilot study on the use of repeated doses of sublingual misoprostol in termination of pregnancy up to 12 weeks of gestation: efficacy and acceptability. Hum Reprod (2002b); 17, 654-658.

14c.Tang OS, Xu J, Cheng L, Lee SWH and Ho PC Pilot study on the use of sublingual misoprostol with mifepristone in termination of first trimester pregnancy up to 9 wecks of gestation. Hum Reprod $(2002 \mathrm{c}) ; 17,1738-1740$.

15. Tang OS, Lau WNT, Ng EHY, Lee SWH and Ho PC Prospective randomized study to compare the use of repeated doses of vaginal with sublingual misoprostol in the management of first trimester silent miscarriages. Hum Reprod (2003): 18. 176-181.

16. Bugalho $A$, Bique $C$, Almeida $L$ and Bergstrom $S$ 1)Application of vaginal misoprostol before cervical dilatation to facilitate first-trimester pregnancy interruption. Obstet Gynecol (1994); 83,729-731.

17. Grimes DA and Cates W Complication from legally induced abortion: a review. Obstet Gynecol. Surv (1979); 34, 177-191.

18. Grimes DA, Schulz KF and Cates W Prevention of uterine perforation during curetlage abortion. J Am Med Assoc (1984); 251, 2108-2111.

19. Henry A and Haukkamaa M Comparison of vaginal misoprostol and gemeprost as pre-treatment in lirst trimester pregnancy interruption. $\mathrm{Br} \mathrm{J}$ Obstet Gynaecol (1999); 106, 540-543. 
Table 1: Demographic data of the 80 women who underwent vacuum evacuation*.

\begin{tabular}{|l|c|c|}
\hline \multicolumn{1}{|c|}{ Character } & $\begin{array}{c}\text { Sublingual } \\
(\mathbf{n}=\mathbf{4 0})\end{array}$ & $\begin{array}{c}\text { Vaginal } \\
(\mathbf{n}=\mathbf{4 0})\end{array}$ \\
\hline Age & $24.2(5.8)$ & $23.3(5.7)$ \\
Parity: (number/ percentage) & $13(32.5 \%)$ & $12(30 \%)$ \\
$\quad$ Nulliparous & $27(67.5)$ & $38(70 \%)$ \\
Parous & $10.5(1.0)$ & $10.0(1.3)$ \\
Gestation (weeks) & $(27.5)$ & $(37.5)$ \\
Women with history of surgical abortion & & \\
\hline
\end{tabular}

* Values are mean (SD) unless otherwise stated

Table II : Outcome of the 80 women who underwent vacuum evacuation**.

\begin{tabular}{|c|c|c|}
\hline Item & $\begin{array}{l}\text { Sublingual } \\
\qquad \mathrm{n}=40)\end{array}$ & $\begin{array}{l}\text { Vaginal } \\
(n=40)\end{array}$ \\
\hline $\begin{array}{l}\text { Baseline cervical dilation (mm): } \\
\text { Mean (SD) } \\
\text { Median (range) }\end{array}$ & $\begin{array}{c}7.6(1.3) \\
8.0(4.5-10) \\
\end{array}$ & $\begin{array}{c}7.7(0.73) \\
8.0(6.0-9.5)\end{array}$ \\
\hline $\begin{array}{l}\text { Poor cervical priming: } \\
\text { (Number : percentage) }\end{array}$ & $8(20 \%)$ & $7(17.5 \%)$ \\
\hline $\begin{array}{l}\text { Blood loss }(\mathrm{ml}) \text { : } \\
\text { Mean (SD) } \\
\text { Median (range) }\end{array}$ & $\begin{array}{l}52.1(20.2) \\
50(10-100)\end{array}$ & $\begin{array}{l}48.3(12.3) \\
50(10-80)\end{array}$ \\
\hline
\end{tabular}

** Values are mean (SD) unless otherwise stated

Table III : Pre-operative side effects in both groups .

\begin{tabular}{|l|c|c|}
\hline \multicolumn{1}{|c|}{ Side Effect } & $\begin{array}{c}\text { Sublingual } \\
(\mathbf{n}=40)\end{array}$ & $\begin{array}{c}\text { Vaginal } \\
(\mathbf{n}=40)\end{array}$ \\
\hline Nausea & $8(20)$ & $14(35)$ \\
\hline Vomiting & $1(2.5)$ & $3(7.5)$ \\
\hline Diarrhea & $1(2.5)$ & $1(2.5)$ \\
\hline Vaginal bleeding & $15(37.5)$ & $9(22.5)$ \\
Scanty & $12(30)$ & $7(17.5)$ \\
Moderate & $3(7.5$ & $1(2.5)$ \\
Heavy & $0(0)$ & $1(2.5)$ \\
\hline Abdominal pain & $34(85)$ & $31(77.5)$ \\
Mild & $22(55$ & $17(42.5)$ \\
Moderate & $11(27.5)$ & $9(22.5)$ \\
Severe & $1(2.5)$ & $5(12.75)$ \\
\hline Passage ol products ol conception before operation & $0(0)$ & $0(0)$ \\
\hline
\end{tabular}

